University of Nebraska - Lincoln

DigitalCommons@University of Nebraska - Lincoln

USDA National Wildlife Research Center - Staff

Publications
U.S. Department of Agriculture: Animal and Plant Health Inspection Service

$5-20-2019$

\title{
Scavenging in the Anthropocene: Human impact drives vertebrate scavenger species richness at a global scale
}

\author{
Esther Sebastián-González \\ Universidad Miguel Hernández, esebgo@gmail.com \\ Jomar Magalhães Barbosa \\ Universidad Miguel Hernández \& Doñana Biological Station-CSIC

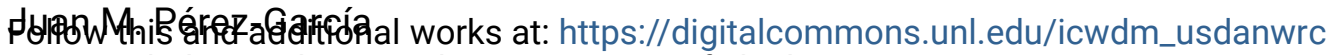 \\ Iniversidad Miguel Hernández \& University of Lleida \\ - Part of the Natural Resources and Conservation Commons, Natural Resources Management and

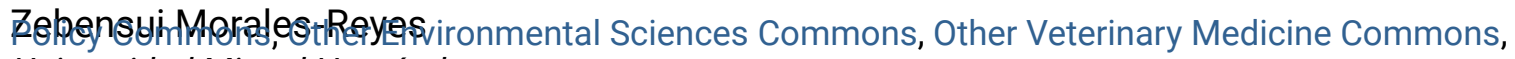 \\ Universidad Miquel Hernández \\ Bniversidadion Biology Commons, Terrestrial and Aquatic Ecology Commons, Veterinary Infectious Diseases \\ Fpancisco Boterilary Microbiology and Immunobiology Commons, Veterinary Preventive Medicine,

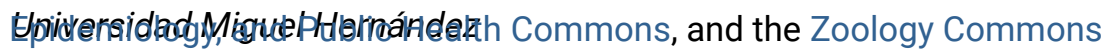

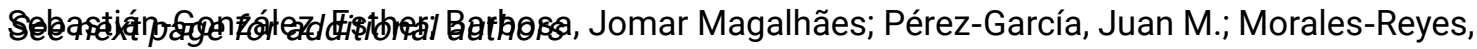
Zebensui; Botella, Francisco; Olea, Pedro P.; Mateo-Tomás, Patricia; Moleón, Marcos; Hiraldo, Fernando; Arrondo, Eneko; Donázar, José A.; Cortés-Avizanda, Ainara; Selva, Nuria; Lambertucci, Sergio A.; Bhattacharjee, Aishwarya; Brewer, Alexis; Abernethy, Erin; Rhodes, Olin E. Jr.; Turner, Kelsey; Beasley, James C.; DeVault, Travis L.; Ordiz, Andrés; Wikenros, Camilla; Zimmermann, Barbara; Wabakken, Petter; Wilmers, Christopher C.; Smith, Justine A.; Kendall, Corinne J.; Ogada, Darcy; Buechley, Evan R.; Frehner, Ethan; Allen, Maximilian L.; Wittmer, Heiko U.; Butler, James R.A.; du Toit, Johan T.; Read, John; Wilson, David; Jerina, Klemen; Krofel, Miha; Kostecke, Rich; Inger, Richard; Samson, Arockianathan; Naves-Alegre, Lara; and Sánchez-Zapata, José A., "Scavenging in the Anthropocene: Human impact drives vertebrate scavenger species richness at a global scale" (2019). USDA National Wildlife Research Center - Staff Publications. 2266.

https://digitalcommons.unl.edu/icwdm_usdanwrc/2266

This Article is brought to you for free and open access by the U.S. Department of Agriculture: Animal and Plant Health Inspection Service at DigitalCommons@University of Nebraska - Lincoln. It has been accepted for inclusion in USDA National Wildlife Research Center - Staff Publications by an authorized administrator of DigitalCommons@University of Nebraska - Lincoln. 


\section{Authors}

Esther Sebastián-González, Jomar Magalhães Barbosa, Juan M. Pérez-García, Zebensui Morales-Reyes, Francisco Botella, Pedro P. Olea, Patricia Mateo-Tomás, Marcos Moleón, Fernando Hiraldo, Eneko Arrondo, José A. Donázar, Ainara Cortés-Avizanda, Nuria Selva, Sergio A. Lambertucci, Aishwarya Bhattacharjee, Alexis Brewer, Erin Abernethy, Olin E. Rhodes Jr., Kelsey Turner, James C. Beasley, Travis L. DeVault, Andrés Ordiz, Camilla Wikenros, Barbara Zimmermann, Petter Wabakken, Christopher C. Wilmers, Justine A. Smith, Corinne J. Kendall, Darcy Ogada, Evan R. Buechley, Ethan Frehner, Maximilian L. Allen, Heiko U. Wittmer, James R.A. Butler, Johan T. du Toit, John Read, David Wilson, Klemen Jerina, Miha Krofel, Rich Kostecke, Richard Inger, Arockianathan Samson, Lara Naves-Alegre, and José A.

Sánchez-Zapata 


\title{
Scavenging in the Anthropocene: Human impact drives vertebrate scavenger species richness at a global scale
}

\author{
Esther Sebastián-González ${ }^{1}$ (D) ｜ Jomar Magalhães Barbosa ${ }^{1,2}$ | Juan M. Pérez-García ${ }^{1,3}$ | \\ Zebensui Morales-Reyes $^{1}$ | Francisco Botella ${ }^{1}$ | Pedro P. Olea ${ }^{4,5}$ |
}

Patricia Mateo-Tomás ${ }^{6,7}$ (D) | Marcos Moleón ${ }^{8}$ | Fernando Hiraldo ${ }^{2}$ | Eneko Arrondo ${ }^{2}$ | José A. Donázar ${ }^{2}$ | Ainara Cortés-Avizanda ${ }^{2,9}$ | Nuria Selva ${ }^{10}$ (D) |

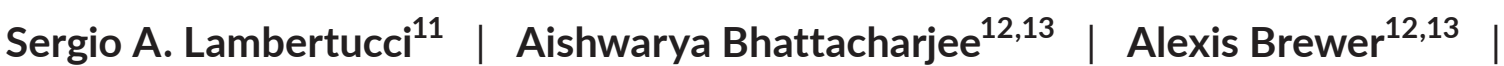

José D. Anadón ${ }^{12,13}$ | Erin Abernethy ${ }^{14}$ | Olin E. Rhodes Jr ${ }^{15}$ | Kelsey Turner ${ }^{15}$ |

James C. Beasley ${ }^{15}$ | Travis L. DeVault ${ }^{16}$ | Andrés Ordiz ${ }^{17}$ | Camilla Wikenros $^{18}$ (D) |

Barbara Zimmermann $^{19}$ | Petter Wabakken ${ }^{19}$ | Christopher C. Wilmers ${ }^{20}$ |

Justine A. Smith ${ }^{21}$ | Corinne J. Kendall ${ }^{22}$ | Darcy Ogada ${ }^{23,24}$ | Evan R. Buechley ${ }^{25,26,27 ~ \mid ~}$

Ethan Frehner ${ }^{25}$ | Maximilian L. Allen ${ }^{28}$ | Heiko U. Wittmer ${ }^{29}$ (D) James R. A. Butler ${ }^{30}$ |

Johan T. du Toit ${ }^{31}$ | John Read ${ }^{32}$ | David Wilson ${ }^{33}$ | Klemen Jerina ${ }^{34}$ |

Miha Krofel $^{34}$ (D) | Rich Kostecke ${ }^{35}$ | Richard Inger ${ }^{36}$ | Arockianathan Samson ${ }^{37}$ (D) |

Lara Naves-Alegre $^{1}$ | José A. Sánchez-Zapata ${ }^{1}$

\footnotetext{
${ }_{1}^{1}$ Departamento de Biología Aplicada, Universidad Miguel Hernández, Elche, Spain

${ }^{2}$ Department of Conservation Biology, Doñana Biological Station-CSIC, Seville, Spain

${ }^{3}$ Department of Animal Science, Faculty of Life Sciences and Engineering, University of Lleida, Lleida, Spain

${ }^{4}$ Centro de Investigación en Biodiversidad y Cambio Global (CIBC-UAM), Universidad Autónoma de Madrid, Madrid, Spain

${ }^{5}$ Departamento de Ecología, Universidad Autónoma de Madrid, Madrid, Spain

${ }^{6}$ Centre for Functional Ecology, Department of Life Sciences, University of Coimbra, Coimbra, Portugal

${ }^{7}$ Biodiversity Research Unit (UMIB), UO-CSIC-PA, Oviedo University, Mieres, Spain

${ }^{8}$ Department of Zoology, University of Granada, Granada, Spain

${ }^{9}$ Animal Ecology and Demography Group, IMEDEA (CSIC-UIB), Esporles, Spain

${ }^{10}$ Institute of Nature Conservation, Polish Academy of Sciences, Krakow, Poland

${ }^{11}$ Grupo de Investigaciones en Bilogía de la Conservación, Laboratorio Ecotono, INIBIOMA (CONICET, Universidad Nacional del Comahue), Bariloche, Argentina

${ }^{12}$ Department of Biology, Queens College, City University of New York, Queens, New York

${ }^{13}$ Biology Program, The Graduate Center, City University of New York, New York, New York

${ }^{14}$ Integrative Biology Department, Oregon State University, Corvallis, Oregon

${ }^{15}$ Savannah River Ecology Lab, Warnell School of Forestry and Natural Resources, University of Georgia, Aiken, South Carolina

${ }^{16}$ National Wildlife Research Center, United States Department of Agriculture, Sandusky, Ohio

${ }^{17}$ Faculty of Environmental Sciences and Natural Resource Management, Norwegian University of Life Sciences, Ås, Norway

${ }^{18}$ Grimsö Wildlife Research Station, Department of Ecology, Swedish University of Agricultural Sciences, Riddarhyttan, Sweden

${ }^{19}$ Faculty of Applied Ecology, Agricultural Sciences and Biotechnology, Inland Norway University of Applied Sciences, Elverum, Norway

${ }^{20}$ Center for Integrated Spatial Research, Environmental Studies Department, University of California, Santa Cruz, California

${ }^{21}$ Department of Environmental Science, Policy, and Management, University of California, Berkeley, California
}

${ }^{22}$ North Carolina Zoo, Asheboro, North Carolina 


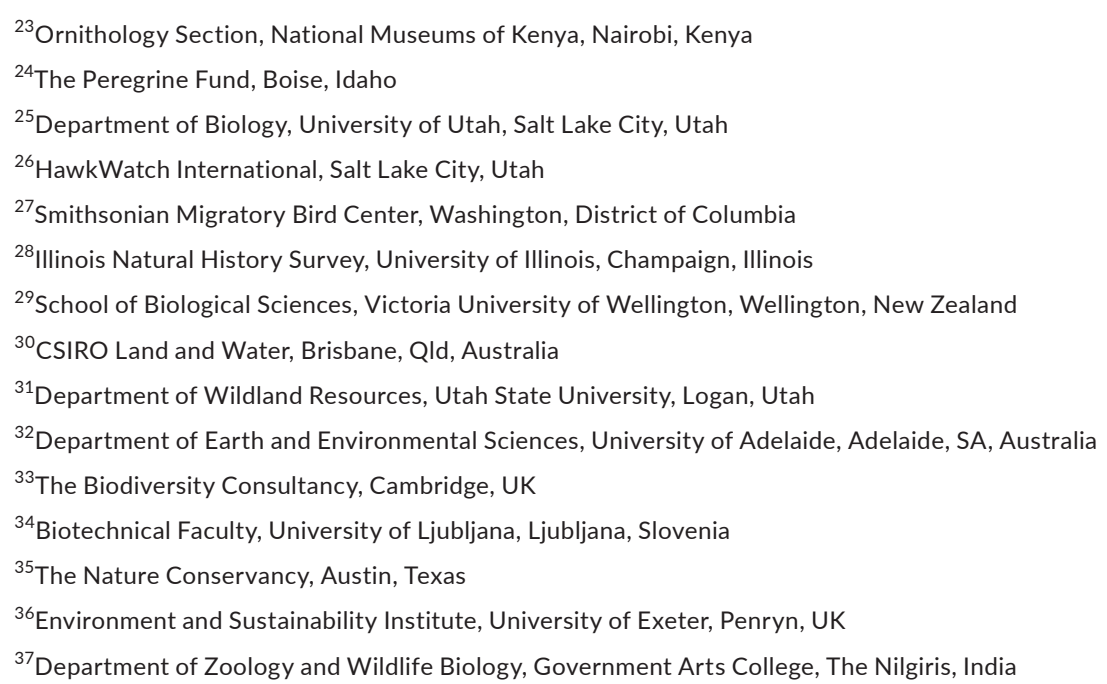

\section{Correspondence}

Esther Sebastián González, Departamento de Biología Aplicada, Universidad Miguel Hernández. Avda, Universidad s/n 03202 Elche, Spain.

Email: esebgo@gmail.com

\section{Funding information}

Gordon and Betty Moore Foundation; Consejería de Economía, Innovación, Ciencia y Empleo, Junta de Andalucía, Grant/Award Number: RNM-1925; Ministerio de Economía y Competitividad, Grant/Award Number: CGL201240013-C02-01/02, CGL2015-66966-C21-R, CGL2017-89905-R, FJCI-2015-25632, IJCI-2014-20744, IJCl-2015-24947 and RYC-2015-19231; National Science Foundation, Grant/Award Number: 1255913 and 1256065 ; U.S. Department of Agriculture, Grant/Award Number: DE-EM0004391; Generalitat Valenciana, Grant/Award Number: SEJI/2018/024; Slovenian Research Agency, Grant/ Award Number: P4-0059; Govern de les Illes Balears, Grant/Award Number: PD/039/2017; La Caixa-Severo Ochoa International PhD Program; The Peregrine Fund; National Science Centre Poland, Grant/Award Number: 2013/08/M/ NZ9/00469; California Department of Fish \& Wildlife

\begin{abstract}
Understanding the distribution of biodiversity across the Earth is one of the most challenging questions in biology. Much research has been directed at explaining the species latitudinal pattern showing that communities are richer in tropical areas; however, despite decades of research, a general consensus has not yet emerged. In addition, global biodiversity patterns are being rapidly altered by human activities. Here, we aim to describe large-scale patterns of species richness and diversity in terrestrial vertebrate scavenger (carrion-consuming) assemblages, which provide key ecosystem functions and services. We used a worldwide dataset comprising 43 sites, where vertebrate scavenger assemblages were identified using 2,485 carcasses monitored between 1991 and 2018. First, we evaluated how scavenger richness (number of species) and diversity (Shannon diversity index) varied among seasons (cold vs. warm, wet vs. dry). Then, we studied the potential effects of human impact and a set of macroecological variables related to climatic conditions on the scavenger assemblages. Vertebrate scavenger richness ranged from species-poor to species rich assemblages (4-30 species). Both scavenger richness and diversity also showed some seasonal variation. However, in general, climatic variables did not drive latitudinal patterns, as scavenger richness and diversity were not affected by temperature or rainfall. Rainfall seasonality slightly increased the number of species in the community, but its effect was weak. Instead, the human impact index included in our study was the main predictor of scavenger richness. Scavenger assemblages in highly human-impacted areas sustained the smallest number of scavenger species, suggesting human activity may be overriding other macroecological processes in shaping scavenger communities. Our results highlight the effect of human impact at a global scale. As speciesrich assemblages tend to be more functional, we warn about possible reductions in ecosystem functions and the services provided by scavengers in human-dominated landscapes in the Anthropocene.
\end{abstract}

\section{KEYWORDS}

carrion, climate, human footprint, latitudinal hypothesis, species diversity 


\section{1 | INTRODUCTION}

Scientists have long tried to disentangle the processes driving the latitudinal biodiversity gradient showing that species diversity is greatest in the tropics and decreases toward the poles (e.g., Hawkins et al., 2003; Schluter, 2016). In a review, Willig, Kauffman and Stevens (2003) listed several hypotheses proposed to explain this pattern. For example, species diversity is expected to be higher in areas with more available environmental energy, in accordance with the Productivity Hypothesis (Pianka, 1966; Willig et al., 2003). This hypothesis posits that the amount of energy available to plants and water availability limit productivity of an ecosystem, affecting all species within trophic chains (Wright, 1983). Similarly, the Physiological Tolerance Hypothesis suggests diversity is limited by the number of species able to tolerate local conditions (Currie et al., 2004). For example, extinction rates in tropical climates are low compared to temperate regions because of climatic stability (Dynesius \& Jansson, 2000). The Evolutionary Speed Hypothesis posits that speciation rates are higher in warmer (tropical) environments because generation times are shorter, mutation rates are higher, and interspecific competition and selection pressures are stronger (Allen, Brown, \& Gillooly, 2002; Currie et al., 2004).

Because of the strong effect of latitude on climate, most hypotheses (such as those above) suggest climatic conditions are the main drivers of variation in species richness, and this is supported by several empirical studies. For example, an increase in the number of vertebrate species has been related to annual potential evapotranspiration, a measure of the energy available in the ecosystem (Currie, 1991). Similarly, productivity, rainfall and temperature explained broad-scale vertebrate richness patterns (Hawkins et al., 2003). In the Anthropocene, however, human-related factors in addition to climate are expected to influence global species distribution patterns, due to the multitude of effects that humans impose on the ecosphere. Because of its pervasiveness, human impact may directly (e.g., by hunting, Benítez-López et al., 2017) and indirectly (e.g., by altering the habitat and amount of food available to species) affect the number of species in a community and their interactions. For example, human factors drive global avian species loss (Jetz, Wilcove \& Dobson, 2007), affect macroecological patterns of seed-dispersal assemblages (Sebastián-González, Dalsgaard, Sandel, \& Guimarães, 2015), and restrict local and regional movements of terrestrial mammal species (Tucker et al., 2018). Thus, assessing the contribution of human impact on species richness and diversity is a pressing ecological challenge in an increasingly humanized world.

Given that global consensus on the species latitudinal processes has not emerged (e.g., Hillebrand, 2004), large-scale investigations of understudied communities are of particular interest. Scavenger assemblages, or species that include carrion in their diets (DeVault, Rhodes, \& Shivik, 2003; Wilson \& Wolkovich, 2011), have received comparatively little attention from the scientific community. Scavengers play pivotal roles in ecosystems by stabilizing food webs (Moleón et al., 2014; Wilson \& Wolkovich, 2011), providing regulating services for organic food waste (O'Bryan et al., 2018), accelerating nutrient recycling (Wilson \& Read, 2003) and removing potential sources of infectious disease transmission (Ogada, Torchin, Kinnaird, \& Ezenwa, 2012). Among all scavenger species, vertebrate scavengers in general and obligate scavengers in particular, are especially important in terrestrial ecosystems because they are able to consume large amounts of carrion in short time periods (DeVault et al., 2003; Morales-Reyes et al., 2017; Sebastián-González et al., 2016). There is some evidence that vertebrate scavenger diversity is lower in biomes with more extreme climatic conditions (e.g., desert or tundra; Mateo-Tomás et al., 2015), and a major impact of human disturbance on the ecosystem functions supported by vertebrate scavenger assemblages has been suggested (Mateo-Tomás, Olea, Moleón, Selva, \& Sánchez-Zapata, 2017). However, a comprehensive study evaluating macroecological patterns in scavenger assemblages is lacking, especially in the context of the human drivers that make current (Anthropocene) conditions unique in evolutionary history.

The goals of our study were twofold. First, we aimed to describe large-scale patterns of species richness (number of species) and diversity (Shannon diversity index) in terrestrial vertebrate scavenger assemblages. We know from previous studies that scavenger communities have a different structure in warm and cold seasons (Selva \& Fortuna, 2007) and that season plays a critical role in how long carcasses are available to be scavenged (e.g., Turner, Abernethy, Conner, Rhodes, \& Beasley, 2017). Also, several scavenger species are migratory, which also calls for the consideration of different seasons. Thus, we also explored the effect of season (cold vs. warm and wet vs. dry) in shaping the patterns of scavenger richness and diversity. We expected to have seasonal differences in the number and diversity of scavenger species. Second, we aimed to identify the main macroecological factors driving terrestrial vertebrate scavenger richness and diversity and tested five climatic, scavenging, and human-related hypotheses (Table 1). We expected scavenger species richness and diversity to be higher in areas that are wetter (Productivity Hypothesis), more stable and thus with lower seasonality (Physiological Tolerance Hypothesis), and warmer (Productivity Hypothesis, Physiological Tolerance Hypothesis, and Evolutionary Speed Hypothesis).

Alternatively, vertebrate scavengers compete with microorganisms and invertebrates for carrion. The latter species may benefit from warm and wet climatic conditions, reducing the temporal window of carcass consumption, and outcompeting vertebrates (DeVault, Brisbin, \& Rhodes, 2004; Ray, Seibold, \& Heurich, 2014). Under this hypothesis, termed "Competitive Hypothesis," richness of the vertebrate assemblage would be reduced in the most warm and wet environments. Moreover, modern human-mediated factors may override evolved latitudinal or ecological patterns, and affect scavenger richness and diversity in both positive and negative ways. On the one hand, humans may increase the availability of carrion from hunting, livestock, or roadkills (Lambertucci, Speziale, Rogers, \& Morales, 2009; Oro, Genovart, Tavecchia, Fowler, \& Martínez-Abraín, 2013), as well as the predictability of carcasses available through wild harvesting (Read \& Wilson, 2004), or artificial feeding stations (Cortés-Avizanda et al., 2016), ultimately benefitting scavengers. On the other hand, habitat modification and loss, or direct persecution may reduce the population viability of many scavenger species, reducing community diversity and richness (Mateo-Tomás, Olea, Selva, \& Sánchez-Zapata, 2018). Here, we used the largest compilation of vertebrate scavenging studies to date to identify the major drivers of scavenger richness and diversity at a global scale. 


\begin{tabular}{|c|c|c|}
\hline Hypothesis & $\begin{array}{l}\text { Main associated } \\
\text { variables }\end{array}$ & Main prediction \\
\hline \multicolumn{3}{|l|}{ Climatic } \\
\hline $\begin{array}{l}\text { Productivity } \\
\text { Hypothesis }\end{array}$ & $\begin{array}{l}\text { Temperature } \\
\text { Rainfall }\end{array}$ & $\begin{array}{l}\text { Higher species richness and diversity in areas } \\
\text { with higher available environmental energy }\end{array}$ \\
\hline $\begin{array}{l}\text { Physiological } \\
\text { Tolerance } \\
\text { Hypothesis }\end{array}$ & $\begin{array}{l}\text { Temperature } \\
\text { seasonality } \\
\text { Rainfall } \\
\text { seasonality }\end{array}$ & $\begin{array}{l}\text { Larger species richness and diversity under } \\
\text { more stable climatic conditions }\end{array}$ \\
\hline $\begin{array}{l}\text { Evolutionary } \\
\text { Speed Hypothesis }\end{array}$ & Temperature & $\begin{array}{l}\text { Larger species richness and diversity in warm } \\
\text { environments where speciation rates are } \\
\text { high }\end{array}$ \\
\hline \multicolumn{3}{|l|}{ Scavenging-related } \\
\hline $\begin{array}{l}\text { Competitive } \\
\text { Hypothesis }\end{array}$ & $\begin{array}{l}\text { Temperature } \\
\text { Rainfall }\end{array}$ & $\begin{array}{l}\text { Lower vertebrate scavenger richness and } \\
\text { diversity under warm and wet climatic condi- } \\
\text { tions, as microorganisms and invertebrates } \\
\text { may overcompete vertebrate scavengers }\end{array}$ \\
\hline \multicolumn{3}{|l|}{ Human-related } \\
\hline $\begin{array}{l}\text { Human impact } \\
\text { overrides other } \\
\text { patterns }\end{array}$ & $\begin{array}{l}\text { Human footprint } \\
\text { (HF) }\end{array}$ & $\begin{array}{l}\text { Reduced species richness and diversity in } \\
\text { areas with higher HF }\end{array}$ \\
\hline
\end{tabular}

TABLE 1 Climatic, scavenging- and human-related hypotheses explaining large-scale patterns in vertebrate scavenger communities

Note: We indicate their associated predictions and the variables included in this study to evaluate hypothesis importance.

\section{2 | METHODS}

\section{1 | Carcass monitoring and scavenger diversity}

We assembled a global dataset consisting of 43 study sites from 17 countries across 5 continents (average number of studies by continent $\pm S D$ : $8.6 \pm 6.8$; range: $2-18$ ) describing the vertebrate scavenger assemblages, comprised of species observed consuming carrion. Data originated from studies performed between 1991 and 2018 when carcasses were located in the field (Figure 1; Appendix S1). Carcass monitoring in all study sites met some minimum requirements to be included in the analyses. All carcasses were either fresh or had been frozen while fresh prior to placement in the field. Only studies using herbivore carcasses (e.g., terrestrial ungulates, rodents, and lagomorphs) were included (see Moleón et al., 2017). Carcasses were monitored either by camouflaged automatic camera traps, from observatories that were far enough to minimize scavenger avoidance, or from indirect signs of scavenger presence at carcass sites. Carcasses were continuously monitored until scavenging ended (only bones and/or skin remained) or the carcass disappeared because a scavenger took it. We only included information on species that were detected consuming carrion. When consumption was suspected, but not clearly recorded, we assumed consumption if that species had already been detected consuming other carcasses in each particular study site. See details on the specific monitoring procedures for each site in the references listed in Appendix S1.

For each study site, we collected information on vertebrate scavenger richness (measured as the total number of scavenger species documented at monitored carcasses at each study site), and the coordinates of the center of the study site. Carcass size ranged from rodents (e.g., 20 g, mice) to large ungulates (e.g., 900 kg, bison). For 37 of the 43 datasets for which quantitative information was available, we computed the scavenger relative abundance as the maximum number of unequivocally different individuals of each species detected at a single carcass. This was calculated by identifying the highest number of individuals of a scavenger species simultaneously observed or appearing in a picture (e.g., Mateo-Tomás et al., 2017; Moleón, SánchezZapata, Sebastián-González, \& Owen-Smith, 2015). For some species (e.g., lions Panthera leo and Andean condors Vultur gryphus), different individuals visiting the same carcass were counted using identifying features like skin patterns, injuries, and sexual dimorphism. As a measure of scavenger diversity, we calculated the Shannon diversity index for each study site based on scavenger relative abundance using the vegan package (Oksanen et al., 2017).

Because one of our goals was also to study seasonal differences in the scavenger community, we assigned each carcass to one season depending on the main climatic changes in the region. We calculated scavenger richness and diversity separately for each season for those study sites monitored across seasons. For most study sites we considered two seasons: cold (fall and winter, $N=23$ ) versus warm (spring and summer, $N=31$ ). However, for those areas where the main climatic seasonal changes are driven by rainfall, we divided them into wet $(N=8)$ versus dry $(N=8)$.

\section{2 | Macroecological drivers}

We explored the proposed hypotheses on how climatic, scavengingrelated, and human-related factors were associated with scavenger 


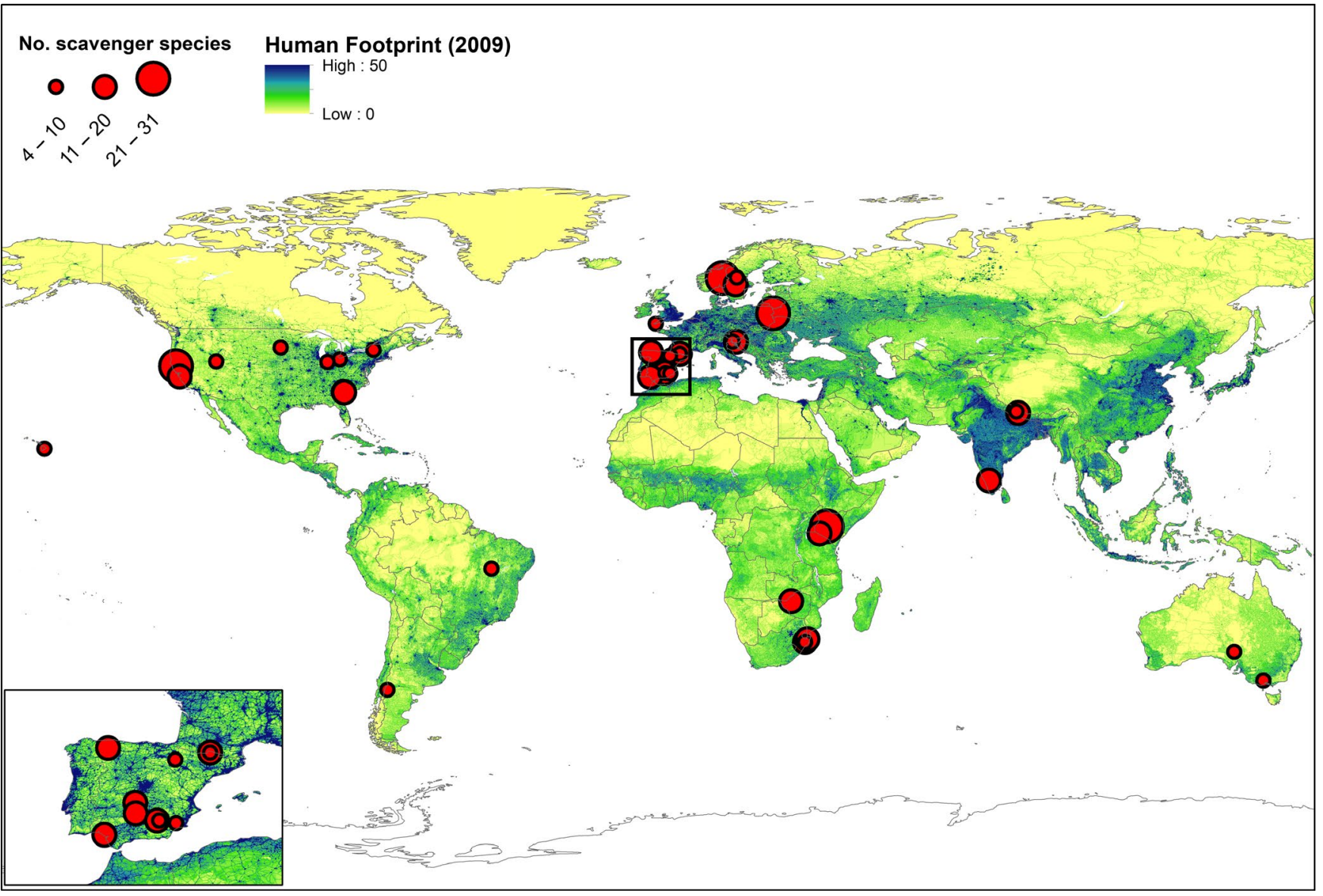

FIGURE 1 Map showing the location of the 43 study sites. Each point represents one study site. The size of the point is related to scavenger richness in the assemblage. In the lower left corner, we show a detail of the study sites conducted in the Iberian Peninsula because of the high number of studies overlapping in this region. The map in the background represents the values of the human footprint variable measured in 2009 [Colour figure can be viewed at wileyonlinelibrary.com]

richness and diversity (Table 1). For each site, we extracted five variables linked to one or several of the hypotheses that explained the latitudinal diversity gradient: (a) mean annual temperature $\left({ }^{\circ} \mathrm{C}\right)$; (b) annual temperature seasonality, calculated as the standard deviation (SD) of mean daytime temperature during the year; (c) mean of the total annual rainfall ( $\mathrm{mm}$ ); (d) annual rainfall seasonality, calculated as the coefficient of variation (SD/mean) of the monthly rainfall during the year; (e) human footprint (HF, Venter et al., 2016).

Mean and SD of temperature $\left({ }^{\circ} \mathrm{C}\right.$ ) between 2001 and 2015, with spatial resolution of $\sim 5 \mathrm{~km}$, were obtained from Oxford Daytime Land Surface Temperature (Weiss et al., 2014). The dataset for this temperature product is Moderate Resolution Imaging Spectroradiometer (MODIS) land surface temperature data (MOD11A2), which was gap filled to eliminate missing data caused by factors such as cloud cover (see Weiss et al., 2014). Mean annual and SD of rainfall (mm/year) between 2001 and 2015 were obtained from the Climate Hazards Group InfraRed Precipitation with Station data (CHIRPS; Funk et al., 2015), which is a quasi-global gridded rainfall time series with $0.05^{\circ}$ spatial resolution. Where CHIRPS data were not available (latitudes higher than $50^{\circ}$ ), we used Global Land Data Assimilation System (Rodell et al., 2004), with $0.25^{\circ}$ spatial resolution, to calculate mean annual and SD rainfall (mm/year) between 2001 and 2015. We calculated the mean annual rainfall by adding up all the rainfall in a pixel throughout the year and then averaging this total annual rainfall across years. HF is an index available in a global dataset of $1 \mathrm{~km}$ grid cells, created from global data layers indicating human population pressure (population density), human land use and infrastructure (built-up areas, night-time lights, land use/land cover), and human access (coastlines, roads, railroads, navigable rivers). HF was downloaded from https://datadryad.org/resource/ doi:10.5061/dryad.052q5. This database provides information with the HF at 2 years: 1993 and 2009, so we assigned to each study site, the $\mathrm{HF}$ value closest to the date when the study was performed.

We calculated the average of all these variables within a spatial extent of $20 \mathrm{~km}$ buffer radio around the center of the coordinates at each study site. This buffer area was selected to represent: (a) local conditions in the area where most of the experimental carcasses were located, (b) regional conditions aiming to account for the landscape heterogeneity in the surroundings of the study site, and (c) to reflect the habitat characteristics of the study sites at the biogeographical scale without dilution from nearby areas with different land uses. Because the climatic variables are derived from a model and have a large spatial resolution $(5 \mathrm{~km})$, we did not 
expect them to change significantly with different spatial extents. However, we also calculated all the variables using a 10 and $30 \mathrm{~km}$ buffer to understand the spatial consistency of our results, and found that the results were similar at all buffer scales (Appendix S2, Tables S2.5-2.6).

We also calculated other covariates that could influence scavenger richness and diversity, including: (a) carcass size; (b) sample size, or number of carcasses monitored; and (c) spatial autocovariance, which is a term accounting for the spatial autocorrelation in the data. Scavenger richness and diversity may depend on available carcass size, with large carcasses providing higher carrion biomass, a greater diversity of distinct food types (e.g., meat, viscera, bone), and feeding opportunities (e.g., tearing, picking, bone-crushing, stealing), as well as carrion availability for longer periods of time (Moleón et al., 2015; Turner et al., 2017). Carcass size was categorized as: small (<2 kg), medium (2-10 kg), and large (>10 kg) adapted from Moleón et al. (2015). Sample size was included because higher numbers of carcasses are expected to contain larger numbers of scavengers, until the community is completely sampled. To account for the spatial autocorrelation in the structure of the scavenger communities, we added a spatial autocovariate (AC) term. AC was computed from the weighted average distance of all neighboring samples, indicating the degree of spatial clustering among dependent variables. We used the autocov_dist function from the spdep library (Bivand, 2015).

Finally, because of the different sample sizes among study sites, we calculated the sample coverage as the number of scavenging species recorded at each site by using both the presence/absence and individual-based abundance data (Chao et al., 2014). With the sample coverage, we estimated the number of species in each site under a complete survey (i.e., when all the species present in an area are surveyed), and we then compared the observed with the estimated species richness to evaluate if we had monitored most of the species present.

\section{3 | Statistical analyses}

We first used generalized linear models (GLMs) to test if there was a latitudinal pattern in scavenger richness and diversity, by relating them with the latitude of each study site.

We then evaluated the relationships between scavenger richness and diversity and macroecological variables critical to our hypotheses using GLMs. To do so, we first calculated variance inflation factors (VIF) for the macroecological predictor variables using the car package (Fox \& Weisberg, 2011) to assess collinearity. Variables exhibiting VIF values exceeding 3 (temperature for scavenger richness and rainfall for scavenger diversity, Zuur, leno, \& Elphick, 2010) were eliminated from the model. In each model, predictor variables were standardized to the same scale (meaning that they were transformed to have a mean of 0 and standard deviation of 1) and sample size (the number of experimental carcasses used in the study) was log-transformed prior to analyses to improve normality.

As the relationships between scavenger richness or diversity and our predictor variables could be nonlinear, we first compared linear and quadratic one-predictor models for latitude and for each macroecological variable and our dependent variables using an Akaike Information Criteria (AIC)-based model selection. We used this information to decide whether each macroecological predictor variable should be included as linear or quadratic in the models for scavenger richness and scavenger diversity.

Finally, we fitted all the possible combinations and subsets of the predictor variables for scavenger richness and scavenger diversity separately. We selected the model with the lowest AICc, but when there was more than one model with a delta AICc $<2$ with respect to the first ranked model, we implemented a model-averaging function in the MuMIn package (Barton, 2013). This function averages parameter estimates across all considered models for each dependent variable where the respective parameter appeared, weighted by the relative importance of each model. We used a Poisson distribution for modeling scavenger richness and a Gaussian distribution for scavenger diversity in all GLM analyses. All analyses were repeated using a database that included only those studies that used camera traps instead of signs or direct observations in the scavenging monitoring $(N=38)$, to account for the imperfect detection of the latter methods. Finally, we calculated the percent of explained deviance (i.e., the amount of variability explained by the model) of each model.

To evaluate if carcass size, sample size and spatial autocovariance affected scavenger richness and diversity, we fitted one-predictor GLMs relating them (see results of this analysis in Appendix S2, Table S2.1). We included the variables that were significantly related $(p<0.05)$ to scavenger richness and diversity as covariates in the multivariate models relating them with latitude and the macroecological variables. Therefore, the most complicated model tested included the significant covariates (carcass size and sample size for scavenger richness, and carcass size for scavenger diversity, see Results) and the five macroecological variables. All analyses were performed in $\mathrm{R}$ version 3.4.1 (R Development Core Team, 2017).

\section{3 | RESULTS}

\subsection{Global-scale diversity patterns in scavenger communities}

Our global dataset included information from 2,485 carcasses in 43 study sites (Figure 1; Appendix S1). We found high variability in scavenger richness and diversity depending on the study site (Table 2). For example, scavenger richness ranged from 4 (in developed areas in UK and Australia) to 30 vertebrate species (in a Polish temperate old-growth forest) from a total of 174 different species (7 reptiles, 79 mammals, and 88 birds; Appendix S3).

The scavenger assemblage also changed depending on the season when the study was performed. We found higher scavenger richness and slightly higher scavenger diversity in cold compared to warm seasons, but these variables did not differ between dry and wet seasons (Figure 2). Finally, when all the assemblages were standardized to an equal sample coverage (0.95), the estimated species richness was highly correlated with the observed richness for both the abundance (Spearman's correlation $r s=0.68, p<0.001$ ) and the incidence data ( $r \mathrm{~s}=0.84, p<0.001$, Appendix S4). 
TAB LE 2 Scavenger richness and diversity (Shannon diversity index) of vertebrate scavenger communities

\begin{tabular}{cccll} 
& Mean \pm SD & Range & $\begin{array}{l}\text { Latitude } \\
\text { coefficient }\end{array}$ & $\begin{array}{l}\text { Latitude } \\
p \text {-value }\end{array}$ \\
\hline $\begin{array}{c}\text { Scavenger } \\
\text { richness }\end{array}$ & $12.4 \pm 6.07$ & $4-30$ & -0.001 & 0.536 \\
$\begin{array}{c}\text { Scavenger } \\
\text { diversity }\end{array}$ & $1.40 \pm 0.49$ & $0.43-2.29$ & 0.002 & 0.317 \\
\hline
\end{tabular}

Note: Mean, standard deviation (SD), and range (minimum-maximum) values are provided. We also show the coefficients and $p$-values for the generalized linear models relating these variables with latitude. The model for scavenger richness included both carcass size (small, medium, or large; see main text for further explanations) and sample size (log-transformed number of carcasses monitored) as covariates, while the model for scavenger diversity included only carcass size (see complete results for these models in Appendix S2, Table S2.2).
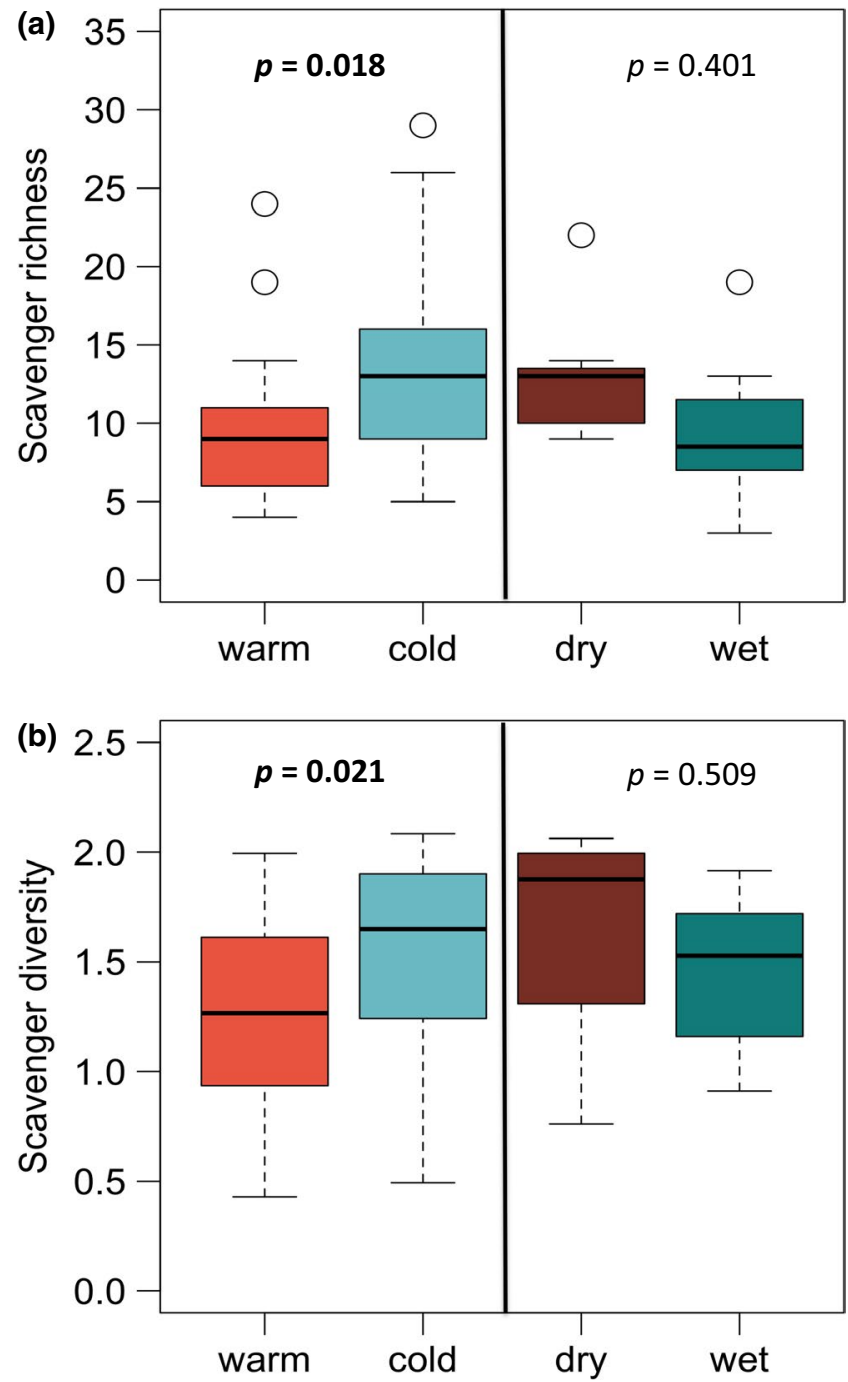

FIGURE 2 Boxplot representing (a) scavenger richness and (b) scavenger diversity (Shannon diversity index) by season. We show the significance of the tests comparing wet versus dry $(n=16)$ and cold versus warm $(n=54)$ seasons by means of pairwise $t$ tests, with significant $p$-values $(<0.05)$ in bold [Colour figure can be viewed at wileyonlinelibrary.com]

\section{2 | Macroecological trends in scavenger diversity}

Contrary to our expectations, scavenger richness and diversity did not show any latitudinal trends and were not affected by most of the climatic variables (Tables 2 and 3; Supporting Information Appendix S2, Table S2.3-2.4 and Figure S2.1). However, the best models for scavenger richness included the variable describing human impact. HF was the main factor influencing scavenger richness in an assemblage, showing a quadratic relationship. When HF was lower than 7, we found more species-poor than species-rich assemblages, which were found more frequently with HF values between 7 and 15; contrastingly, scavenging assemblages at very high HF values (>15) exhibited low scavenger richness (Table 3, Figure 3a; Appendix S2, Tables S2.32.4). There also seems to be a reduction in the variability of scavenger richness values around the mean, with an increase in HF (Appendix S2, Figure S2.2). Rainfall seasonality was also included in the averaged model for species diversity, but, as for species richness, its effect was not significant (Figure 3b). The results were similar at the other two spatial extents (10 and $30 \mathrm{~km}$, Appendix S2, Tables S2.5-2.6), supporting our alternative hypothesis that human impact overrides other patterns.

The only variable that affected both species richness and diversity was carcass size (Table 3, Figure 4a,b). Large carcasses were consumed by more scavenger species, but scavenger diversity was greater at medium-sized carcasses. Finally, scavenger richness also increased with sample size (number of experimental carcasses used in each study, Table 3, Figure 4c). The results did not change when only studies using camera traps were used for the analyses $(N=38$, Appendix S5).

TAB LE 3 GLMs relating scavenger richness and diversity (Shannon diversity index) with the macroecological variables calculated at $20 \mathrm{~km}$ buffer extent

\begin{tabular}{|lll|}
\hline & $\begin{array}{l}\text { Scavenger } \\
\text { richness }\end{array}$ & $\begin{array}{l}\text { Scavenger } \\
\text { diversity }\end{array}$ \\
\hline Sample size (log) & $0.362^{* * *}$ & - \\
\hline Carcass size: small & $-0.804^{* * *}$ & -0.361 \\
\hline Carcass size: medium & -0.182 & $0.367^{*}$ \\
\hline Carcass size: large & $2.585^{* * *}$ & $1.355^{* * *}$ \\
\hline Human footprint & -0.081 & - \\
\hline Human footprint ${ }^{2}$ & $-0.144^{* *}$ & - \\
\hline Rainfall seasonality & 0.054 & 0.090 \\
\hline$n$ & 43 & 37 \\
\hline \% Explained deviance & 57.53 & 19.86 \\
\hline
\end{tabular}

Note: We present the model averaged coefficients of each variable for models with delta $\mathrm{AICC}<2$, with respect to the model with the lowest AICc.

Significant $p$-values are highlighted in bold. We also show the percentage of explained deviance of the model (i.e., the proportion of the variability explained by the model) and the number of studies included in the analyses ( $n$ ). Human Footprint ${ }^{2}$ is the quadratic term of the human footprint variable.

${ }^{* * *} p<0.001,{ }^{* *} p<0.01,{ }^{*} p<0.05$ 

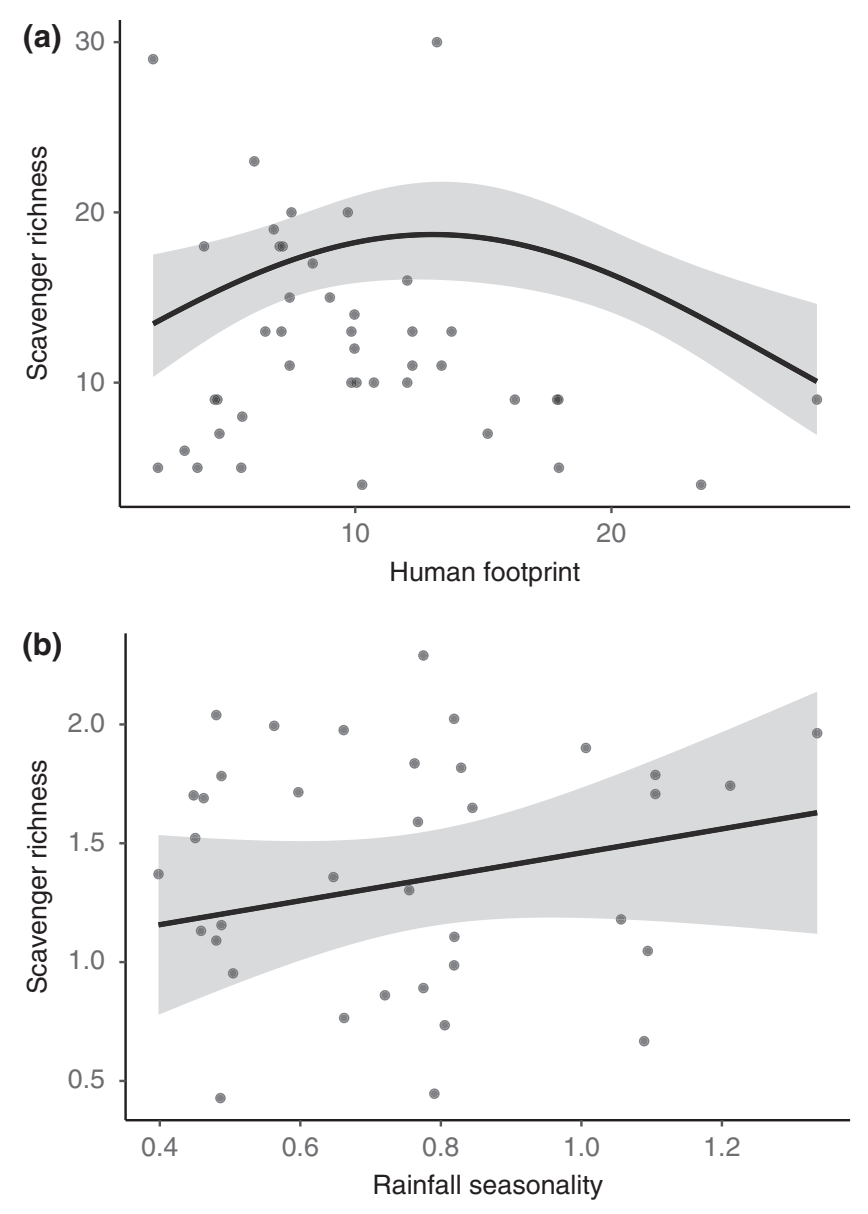

FIGURE 3 Relationships between scavenger richness and the two macroecological variables included in the averaged model: (a) human footprint and (b) rainfall seasonality. The plots show the relationships predicted by the averaged model (black line) and the 95\% confidence interval for scavenger richness (gray shade)

\section{4 | DISCUSSION}

Our results provide evidence that human impact is a dominant factor shaping animal communities worldwide (Jetz et al.., 2007; Sebastián-González et al., 2015; Tucker et al., 2018). The humanrelated factor was the only macroecological variable included in the best models for scavenger richness. Our data (Figure 3) clearly show that regions with low human impact contained both species-rich and species-poor vertebrate scavenger assemblages, while highly developed areas always had low vertebrate scavenger species. HF combines information on human population density, harvest, livestock, land use, land change, and human accessibility. All of these factors are known to affect vertebrates (e.g., Tucker et al., 2018), to predict extinction risk (Di Marco, Venter, Possingham, \& Watson, 2018), and to negatively affect particular scavenger species, at least at the local scale (e.g., Bogoni et al., 2016; Lambertucci et al., 2009). However, this is the first time that human impacts have been shown to be more important than the climatic attributes in driving scavenger species richness at the global scale.
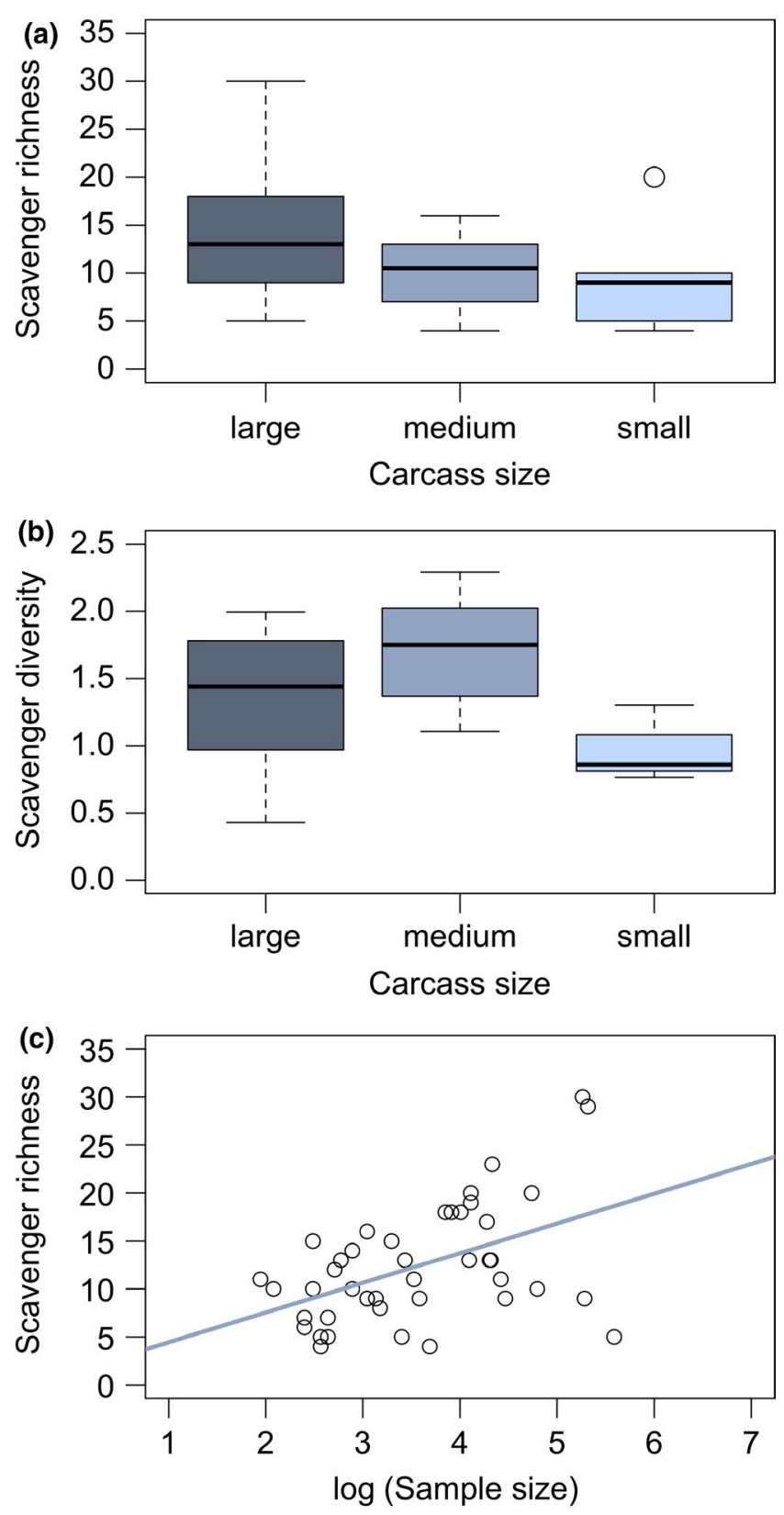

FIGURE 4 Relationships between scavenger richness and diversity, and the covariates, as inferred from generalized linear models averaging: (a, b) carcass size, (c) sample size. For sample size, we also show the regression line for the relationships. Note that the graph represents the pure relationships between the two variables [Colour figure can be viewed at wileyonlinelibrary.com]

\subsection{Effect of human impact}

The loss of animal species, or defaunation, in humanized regions occurs at the global scale (Dirzo et al., 2014), and it also seems to be an important process shaping the observed macroecological patterns in terrestrial vertebrate scavenger species richness. Indeed, two of the main scavenger functional groups, obligate scavengers and top predators, are among the most threatened species worldwide (IUCN, 2018). More importantly, human impact (e.g., human population density, intensification in land use, and land accessibility) is expected to increase, threatening 
the maintenance of the ecosystem functions and services provided by scavengers (DeVault et al., 2016). In areas where the most endangered species in the scavenger community (i.e., obligate scavengers and top predators) have become rare or absent, carrion may remain in the field for longer periods of time, leading to an increase in generalist scavengers that are less efficient at removing carcasses (Mateo-Tomás et al., 2017; Morales-Reyes et al., 2017). This may have several consequences, such as increasing the risk of pests and infectious disease transmission (Buechley \& Şekercioğlu, 2016; Ogada et al., 2012) or slowing down the cycling of nutrients (Moore et al., 2004). For example, the crash of vulture populations in the Indian subcontinent due to a veterinary drug seemed to increase the population of feral dogs and consequently the incidence of rabies (Markandya et al., 2008). Such changes in vertebrate scavenger guilds may also have consequences for ecosystem functioning as species-rich communities are typically more efficient (SebastiánGonzález et al., 2016), promoting the stability of ecosystem processes and the services provided to humans (Moleón et al., 2014).

Moreover, we found a quadratic relationship between scavenger richness and $\mathrm{HF}$, so that the highest values of species richness were found in areas with a certain level of human impact. The quadratic relationship suggests a decrease in scavenger richness in areas with low to medium HF (<7). In some cases, moderate human impact can increase availability of carcasses through roadkill, livestock, or offcuts from wild harvests (Lambertucci et al., 2009; Read \& Wilson, 2004), thus benefiting scavengers. For example, in Guinea-Bissau, hooded vultures Necrosyrtes monachus were more frequently found in densely populated areas where there is a higher garbage availability (Henriques et al., 2018). Also, the highest values of habitat suitability for the endangered Egyptian vulture Neophron percnopterus were found in areas of intermediate livestock density (Mateo-Tomás \& Olea, 2015). However, highly human-impacted areas become unavailable for many scavenger species because of habitat reduction and fragmentation, pollution, or direct persecution (e.g., Huijbers, Schlacher, Schoeman, Weston, \& Connolly, 2013; Lambertucci et al., 2018). Combined, our results suggest that scavenger communities may benefit from some degree of human impact, but are sensitive to high human perturbation (Oro et al., 2013). From a conservation and management perspective, finding that human factors are more important than the climatic attributes for species richness at the global scale is yet another reminder that human decisions may favor or reduce the capacity of ecosystems to retain species richness and associated functions and services.

\subsection{Lack of support for latitudinal hypotheses}

In general, the hypotheses previously proposed to explain latitudinal patterns in species richness were not supported by our data, as scavenger richness and diversity were not affected by temperature or rainfall. Rainfall seasonality slightly increased the number of species in the community, contrary to the predictions of the Physiological Tolerance Hypothesis (Currie et al., 2004). However, its effect was overall very weak. Scavenging-related and human-related hypotheses seemed more appropriate in explaining this pattern as human impact may be overriding the effect of environmental variables (e.g., Nogués-Bravo, Araújo, Romdal, \& Rahbek, 2008). Additionally, high temperatures are linked to increased productivity or evolutionary speed (Allen et al., 2002; Currie et al., 2004; Pianka, 1966; Willig et al., 2003), which may lead to higher scavenger richness. However, at the same time, high temperatures may be enhancing the competitive interactions of vertebrates with microorganisms and invertebrates, because the latter are benefitted from warm temperatures (DeVault et al., 2004; Ray et al., 2014). These two forces may be affecting scavenger species richness concurrently with opposite effects, thus counteracting each other and preventing the appearance of an effect of temperature on scavenger species richness.

\subsection{Effect of covariates}

As expected, the size of the carcasses in each site affected the macroecological patterns described in this study. Carcass size has already been described as a major driver of scavenger assemblage richness and structure (Moleón et al., 2015; Turner et al., 2017). Larger carcasses are detected faster and consumed at higher rates, but the longer availability of the carrion resource permits its consumption by a larger number of scavenger species compared to smaller carcasses, which are usually consumed entirely by a single scavenger (Moleón et al., 2015). Moreover, large carcasses also allow niche specialization where different species utilize different carcass parts (e.g., lappet-faced vultures Torgos tracheliotos feeding on skin and Egyptian vultures eating remains on bones). Interestingly, in contrast to species richness, scavenger diversity reached the highest values in medium-sized carcasses, maybe because of the lower ability of large dominant scavengers (i.e., top predators and vultures) to gather at such carcasses and exclude other species (Moleón et al., 2015; Pardo-Barquín, Mateo-Tomás, \& Olea, 2019). Besides, top predators and vultures can frequently monopolize large carcasses, thus resulting in lower species richness and/or diversity (Pardo-Barquín et al., 2019), while small carcasses are mainly used by mesopredators (Moleón et al., 2015).

\subsection{Seasonal changes}

Our study also shows that species richness and diversity of terrestrial vertebrate scavenger assemblages vary among seasons. Several factors may be increasing the scavenger richness and diversity in the cold season. For example, the cold season typically has less food resources and harsher climatic conditions in temperate ecosystems (e.g., Selva \& Fortuna, 2007). This is reflected in greater availability of carrion through natural deaths and a higher number of species adding carrion as a food source (Turner et al., 2017). In some areas, dominant scavengers known to monopolize carcasses such as bears (Ursus spp.) hibernate during the cold seasons (Allen, Elbroch, Wilmers, \& Wittmer, 2014), enabling other species to use carcasses as a resource. Also, in highly seasonal areas, facultative scavengers may be more predatory during the productive season because prey is more easily available (e.g., vulnerable neonates, migrating 
species), and so they may be less dependent on scavenging (Pereira, Owen-Smith, \& Moleón, 2014). Finally, carrion decomposition by invertebrates and microorganisms slows down when temperatures are low, and carrion is therefore available over a longer time period (DeVault et al., 2004). Conversely, we did not find significant differences between the wet and dry season. Carrion availability in warm regions tends to peak at the end of the dry season (Pereira et al., 2014). However, the differences in resource availability between wet and dry seasons may be less extreme than in regions where the seasons are characterized by cold and warm periods, especially in areas where long-distance ungulate migrations are absent or artificially prevented.

\subsection{Caveats and future directions}

We only considered a species to be a scavenger in a region if it was documented consuming carrion during one of the experimental studies used in our analyses (Appendix S1). Our approach thus ignores other species known to be present in the areas that are likely scavengers, such as species that are known from other studies to consume carrion. An alternative approach would be to use lists of scavenger species present in different regions rather than only those species documented to scavenge during our evaluations of carcass consumption. This alternative approach might eliminate the potential bias of differences in the experimental approach used in each empirical study, such as the differences in carcass size or type. However, we chose not to pursue this alternative approach for two reasons. First, lists of species present in a region, especially in understudied regions, are often incomplete and in some cases not available. Second, and perhaps more importantly, even if a species has been documented as a member of the scavenging community in one region it does not necessarily mean that is also scavenges in other portions of its range due to changing dietary choices or competitive interactions (e.g., Sebastián-González et al., 2016). Therefore, we chose to use only data from studies that documented scavenging behavior under the conditions of the study site.

Relative scavenger abundance, and thus diversity, was calculated as the maximum number of different individuals of each species detected at a single carcass. This is the best measure of abundance we could get, but is unavoidably biased for solitary species lacking skin patterns or sexual dimorphism because it is impossible to differentiate among individuals, and so their relative abundances will always appear low. An alternative method of measuring abundance would be to count the total number of individuals of a given species in each photograph. However, this measure may count the same individual several times and might bias toward species that visit the carcasses for longer periods of time. More importantly, in our study, using the total number of individuals of a species may be misleading because data were collected using different experimental designs. For example, authors set camera traps to have refractory periods from $30 \mathrm{~s}$ to $5 \mathrm{~min}$. This may result in a large variance in the number of individuals detected, which is related to the experimental design instead of real biological differences. An alternative for estimating relative species abundance for future studies would be to estimate the mean visit time of an individual to a carcass and use this estimate to minimize recounts of the same individuals. Unfortunately, the information currently available is still scarce to do it for most of the species studied. Moreover, data based on observations cannot be measured using this approach, so we decided not to use it in our study. We also acknowledge that the population and community metrics of abundance, richness, and diversity can often obscure considerable shifts within species assemblages (Read, Parkhurst, $\&$ Delean, 2015) and hence nonsignificant effects of variables on population metrics does not necessarily mean these same variables will not exert profound influence on species composition and conservation status.

The spatial resolution of the climate (rainfall and temperature) datasets was low and heterogeneous. Low spatial resolution and imbalanced scale in remote-sensing data can propagate noise into models and mask local-level effects of environmental conditions, which may negatively impact the percentage of explained deviance in model. Nevertheless, the value of these global remote-sensing datasets to macroecology is well documented and their hypertemporal availability provides valuable insights into temporal oscillation of climate conditions.

Another consideration is that our metric of human impact (HF) is based on information on human population density, land use, land change, and human access, but not other specific factors that directly affect scavengers, such as animals killed through vehicle collisions or the use of poisons. Thus, our analysis does not link the HF with species-specific threats known to cause declines (i.e., Allan et al., 2019). The HF metric combines several variables and we cannot separate the relative importance and effect that each have on scavengers using only this variable. Thus, we encourage further studies focusing on disentangling how the different aspects of human pressure affect scavenger communities.

Finally, despite considerable effort invested in searching for data on scavenger assemblages, our dataset is clearly unbalanced in space. There is an overrepresentation of study sites in Western Europe and the United States, whereas other regions such as Australia, Asia, and South America contributed a small number of studies (see Figure 1). Similarly, we lack study sites on large extents of the tropical vegetation, deserts and boreal forests, so some particularities of these biomes may not be considered here. For example, there are large areas such as the Sahel, for instance, with light HFs (low road and infrastructure densities) but high human pressure on scavengers (Anadón, Sánchez-Zapata, Carrete, Donázar, \& Hiraldo, 2010). Finally, it is also important to notice that most of the regions assessed in this study are located in human-dominated areas, and we lack sites from the most diverse regions in the planet. Despite having an unbalanced sample distribution toward areas in temperate latitudes, the importance of HF over climatic and latitudinal factors could be expected to increase with a more balanced sample since most of the study sites considered are located in regions with higher human pressure than underrepresented regions (e.g., tropical and subtropical biomes). Thus, more complete gradients of the 
environmental conditions should be investigated using new datasets from understudied regions.

\section{5 | CONCLUSION}

Our study highlights a novel consequence of the global changes driven by human impact in the Anthropocene. Latitudinal or climatic patterns did not seem to be the main drivers of the number of terrestrial vertebrate scavenger species in the assemblages, but we found that scavenger species richness was low in highly human-impacted areas. This loss of scavengers may have detrimental consequences for the conservation and functioning of the ecosystems where these species live, reducing the quality and efficiency of the ecosystem services provided by scavengers. Thus, we urge for specific management and conservation actions to preserve scavengers and their functions worldwide.

Actions should include effective conservation plans of the most globally endangered scavengers (vultures, raptors, and top predators) threatened by poisoning, veterinary drugs, persecution, and mortality associated with infrastructures (power lines, wind farms, and roads; e.g., Botha et al., 2017). Furthermore, actions favoring traditional extensive farming systems and strengthening the link between farmers and nature can be a strategic tool for fostering positive perceptions of scavengers (Morales-Reyes et al., 2018), and promoting their conservation and the ecosystem services they provide. Both actions match within the strategic goals of UN Biodiversity Targets (https://www.cbd.int/sp/targets/, particularly those of strategies $C \& D$ ) and should be addressed and reinforced on their upcoming renewal.

\section{ACKNOWLEDGEMENTS}

ESG, JMPG, and ACA were supported by Juan de la Cierva contracts (Ministerio de Economía y Competitividad, MEC; IJCI-2015-24947, FJCl-2015-25632, and IJCI-2014-20744, respectively). ESG was also supported by Generalitat Valenciana (SEJI/2018/024), ACA by the Govern de les Illes Balears (PD/039/2017), and MM by a Ramón y Cajal contract (MEC; RYC-2015-19231). EA was supported by La Caixa-Severo Ochoa International PhD Program 2015. NS was partly supported by the National Science Centre in Poland (2013/08/M/ NZ9/00469). SAL thanks PICT (BID) 0725/2014. MK and KJ were supported by the Slovenian Research Agency (P4-0059). Contributions of KT and JCB were partially supported through funding from U.S. Department of Agriculture, the U.S. Department of Energy under (DE-EM0004391) to the University of Georgia Research Foundation. EB and EF were supported by the USA National Science Foundation. CK completed study under research permit NCST/5/002/R/448 with support from Hawk Mountain Sanctuary, The Peregrine Fund, and via Pompeo M. Maresi Memorial Fund via Princeton University. JAS and CCW were supported by the USA National Science Foundation \#1255913 and the Gordon and Betty Moore Foundation. Several authors were funded by funds from the
MEC (CGL2012-40013-C02-01/02, CGL2015-66966-C2-1-R and CGL2017-89905-R) and from the Junta de Andalucía (RNM-1925). We are grateful to Orr Spiegel and two anonymous reviewers for very constructive reviews.

\section{ORCID}

Esther Sebastián-González (iD https://orcid.org/0000-0001-7229-1845 Patricia Mateo-Tomás (iD https://orcid.org/0000-0001-6762-9514

Nuria Selva (iD https://orcid.org/0000-0003-3389-201X

Camilla Wikenros (iD https://orcid.org/0000-0002-2825-8834

Heiko U. Wittmer (iD https://orcid.org/0000-0002-8861-188X

Miha Krofel iD https://orcid.org/0000-0002-2010-5219

Arockianathan Samson iD https://orcid.org/0000-0002-0804-7941

\section{REFERENCES}

Allan, J. R., Watson, J. E. M., Di Marco, M., O'Bryan, C. J., Possingham, H. P., Atkinson, S. C., \& Venter, O. (2019). Hotspots of human impact on threatened terrestrial vertebrates. PLoS Biology, 17(3), e3000158. https://doi.org/10.1371/journal.pbio.3000158

Allen, A. P., Brown, J. H., \& Gillooly, J. F. (2002). Global biodiversity, biochemical kinetics, and the energetic-equivalence rule. Science, 297, 1545-1548. https://doi.org/10.1126/science.1072380

Allen, M. L., Elbroch, L. M., Wilmers, C. C., \& Wittmer, H. U. (2014). Trophic facilitation or limitation? Comparative effects of pumas and black bears on the scavenger community. PLoS ONE, 9(7), e102257. https://doi.org/10.1371/journal.pone.0102257

Anadón, J. D., Sánchez-Zapata, J. A., Carrete, M., Donázar, J. A., \& Hiraldo, F. (2010). Large-scale human effects on an arid African raptor community. Animal Conservation, 13, 495-504. https://doi. org/10.1111/j.1469-1795.2010.00369.x

Barton, K. (2013). MuMIn: Multi-model inference. R package, version 1.9.5. Retrieved from http://CRAN.Rproject.org/package=MuMIn

Benítez-López, A., Alkemade, R., Schipper, A. M., Ingram, D. J., Verweij, P. A., Eikelboom, J. A. J., \& Huijbregts, M. A. J. (2017). The impact of hunting on tropical mammal and bird populations. Science, 356, 180-183. https://doi.org/10.1126/science.aaj1891

Bivand, R. (2015). Spatial dependence: Weighting schemes, statistics and models. Retrieved from https://cran.r-project.org/web/packages/ spdep/spdep.pdf

Bogoni, J. A., Cherem, J. J., Hettwer Giehl, E. L., Oliveira-Santos, L. G., de Castilho, P. V., Picinatto Filho, V., ... Graipel, M. E. (2016). Landscape features lead to shifts in communities of medium- to large-bodied mammals in subtropical Atlantic Forest. Journal of Mammalogy, 97, 713-725. https://doi.org/10.1093/jmammal/ gyv215

Botha, A., Andevski, J., Bowden, C. G. R., Gudka, M., Safford, R. J., Tavares, J., \& Williams, N. P. (2017). Multi-species Action Plan to Conserve African-Eurasian Vultures (Vulture MsAP) (CMS TS No. 35). Retrieved from https://www.cms.int/raptors/en/workinggroup/ multi-species-action-plan-conserve-african-eurasian-vultures

Buechley, E. R., \& Şekercioğlu, Ç. H. (2016). The avian scavenger crisis: Looming extinctions, trophic cascades, and loss of critical ecosystem functions. Biological Conservation, 198, 220-228. https://doi. org/10.1093/jmammal/gyv215

Chao, A., Gotelli, N., Hsieh, T. C., Sander, E., Ma, K. H., Colwell, R. K., \& Ellison, A. M. (2014). Rarefaction and extrapolation with Hill numbers: A framework for sampling and estimation in species 
diversity studies. Ecological Monographs, 84, 45-67. https://doi. org/10.1890/13-0133.1

Cortés-Avizanda, A., Blanco, G., DeVault, T. L., Markandya, A., Virani, M. Z., Brandt, J., \& Donázar, J. A. (2016). Supporting feeding and endangered species: Benefits, caveats, and controversies. Frontiers in Ecology and the Environment, 14(4), 191-199. https://doi.org/10.1002/ fee.1257

Currie, D. J. (1991). Energy and large-scale patterns of animal and plant-species richness. American Naturalist, 137, 27-49. https://doi. org/10.1086/285144

Currie, D. J., Mittelbach, G. G., Cornell, H. V., Field, R., Guegan, J.-F., Hawkins, B. A., ... Turner, J. R. G. (2004). Predictions and tests of climate-based hypotheses of broad-scale variation in taxonomic richness. Ecology Letters, 7, 1121-1134. https://doi. org/10.1111/j.1461-0248.2004.00671.x

DeVault, T. L., Beasley, J. C., Olson, Z. H., Moleón, M., Carrete, M., Margalida, A., \& Sánchez-Zapata, J. A. (2016). Ecosystem services provided by avian scavengers. In C. H. Şekercioğlu, D. G. Wenny, \& C. J. Whelan (Eds.), Why birds matter: Avian ecological function and ecosystem services (pp. 235-270). Chicago, IL: University of Chicago Press.

DeVault, T. L., Brisbin, I. L., \& Rhodes, O. E. Jr (2004). Factors influencing the acquisition of rodent carrion by vertebrate scavengers and decomposers. Canadian Journal of Zoology, 82, 502-509. https://doi. org/10.1139/z04-022

DeVault, T. L., Rhodes, O. E., \& Shivik, J. A. (2003). Scavenging by vertebrates: Behavioral, ecological, and evolutionary perspectives on an important energy transfer pathway in terrestrial ecosystems. Oikos, 102, 225-234. https://doi.org/10.1034/j.1600-0706.2003.12378.x

Di Marco, M., Venter, O., Possingham, H. P., \& Watson, J. E. M. (2018). Changes in human footprint drive changes in species extinction risk. Nature Communications, 9, 1-9. https://doi.org/10.1038/ s41467-018-07049-5

Dirzo, R., Young, H. S., Galletti, M., Ceballos, G., Nick, J. B., \& Collen, B. (2014). Defaunation in the Anthropocene. Science, 345, 401-406. https://doi.org/10.1126/science.1251817

Dynesius, M., \& Jansson, R. (2000). Evolutionary consequences of changes in species geographical distributions driven by Milankovitch climate oscillations. Proceedings of the National Academy of Sciences of the United States of America, 97, 9115-9120. https://doi.org/10.1073/ pnas.97.16.9115

Fox, J., \& Weisberg, S. (2011). An R companion to applied regression (2nd edn.). Thousand Oaks, CA: SAGE Publications.

Funk, C., Peterson, P., Landsfeld, M., Pedreros, D., Verdin, J., Shukla, S., ... Michaelsen, J. (2015). The climate hazards infrared precipitation with stations-A new environmental record for monitoring extremes. Scientific Data, 2(1). https://doi.org/10.1038/sdata.2015.66

Hawkins, B. A., Field, R., Cornell, H. V., Currie, D. J., Guégan, J.-F., Kaufman, D. M., ... Turner, J. R. G. (2003). Energy, water, and broadscale geographic patterns of species richness. Ecology, 84, 31053117. https://doi.org/10.1890/03-8006

Henriques, M., Granadeiro, J. P., Monteiro, H., Nuno, A., Lecoq, M., Cardoso, P., ... Catry, P. (2018). Not in wilderness: African vulture strongholds remain in areas with high human density. PLoS ONE, 13(1), e0190594. https://doi.org/10.1371/journal.pone.0190594

Hillebrand, H. (2004). On the generality of the latitudinal diversity gradient. American Naturalist, 163, 192-211. https://doi. org/10.1086/381004

Huijbers, C. M., Schlacher, T. A., Schoeman, D. S., Weston, M. A., \& Connolly, R. M. (2013). Urbanisation alters processing of marine carrion on sandy beaches. Landscape and Urban Planning, 119, 1-8. https ://doi.org/10.1016/j.landurbplan.2013.06.004

IUCN. (2018). The IUCN red list of threatened species. Version 2018-1. Retrieved from http://www.iucnredlist.org
Jetz, W., Wilcove, D. S., \& Dobson, A. P. (2007). Projected impacts of climate and land-use change on the global diversity of birds. PLoS Biology, 5(6), e157. https://doi.org/10.1371/journal.pbio.0050157

Lambertucci, S., Navarro, J., Sánchez-Zapata, J. A., Hobson, K. A., Alarcón, P., Wiemeyer, G., ... Donázar, J. A. (2018). Tracking data and retrospective analyses of diet reveal the consequences of loss of marine subsidies for an obligate scavenger, the Andean condor. Proceedings of the Royal Society B: Biological Sciences, 285, 20180550. https://doi.org/10.1098/rspb.2018.0550

Lambertucci, S. A., Speziale, K. L., Rogers, T. E., \& Morales, J. M. (2009). How do roads affect the habitat use of an assemblage of scavenging raptors? Biodiversity and Conservation, 18, 2063-2074. https://doi. org/10.1007/s10531-008-9573-3

Markandya, A., Taylor, T., Longo, A., Murty, M. N., Murty, S., \& Dhavala, K. (2008). Counting the cost of vulture decline - An appraisal of the human health and other benefits of vultures in India. Ecological Economics, 67, 194-204. https://doi.org/10.1016/j.ecole con.2008.04.020

Mateo-Tomás, P., \& Olea, P. P. (2015). Livestock-driven land use change to model species distributions: Egyptian vulture as a case study. Ecological Indicators, 57, 331-340. https://doi.org/10.1016/j.ecoli nd.2015.05.017

Mateo-Tomás, P., Olea, P. P., Moleón, M., Selva, N., \& Sánchez-Zapata, J. A. (2017). Both rare and common species support ecosystem services in scavenger communities. Global Ecology and Biogeography, 26, 1459-1470. https://doi.org/10.1111/geb.12673

Mateo-Tomás, P., Olea, P. P., Moleón, M., Vicente, J., Botella, F., Selva, N., ... Sánchez-Zapata, J. A. (2015). From regional to global patterns in vertebrate scavenger communities subsidized by big game hunting. Diversity and Distributions, 21, 913-924. https://doi.org/10.1111/ ddi.12330

Mateo-Tomás, P., Olea, P. P., Selva, N., \& Sánchez-Zapata, J. A. (2018). Species and individual replacements contribute more than nestedness to shape vertebrate scavenger metacommunities. Ecography, 42(2), 365-375. https://doi.org/10.1111/ecog.03854

Moleón, M., Martínez-Carrasco, C., Muellerklein, O. C., Getz, W. M., Muñoz-Lozano, C., \& Sánchez-Zapata, J. A. (2017). Carnivore carcasses are avoided by carnivores. Journal of Animal Ecology, 86, 11791191. https://doi.org/10.1111/1365-2656.12714

Moleón, M., Sánchez-Zapata, J. A., Margalida, A., Carrete, M., OwenSmith, N., \& Donázar, J. A. (2014). Humans and scavengers: The evolution of interactions and ecosystem services. BioScience, 64, 394-403. https://doi.org/10.1093/biosci/biu034

Moleón, M., Sánchez-Zapata, J. A., Sebastián-González, E., \& OwenSmith, N. (2015). Carcass size shapes the structure and functioning of an African scavenging assemblage. Oikos, 124, 1391-1403. https:// doi.org/10.1111/oik.02222

Moore, J. C., Berlow, E. L., Coleman, D. C., Ruiter, P. C., Dong, Q., Hastings, A., ... Wall, D. H. (2004). Detritus, trophic dynamics and biodiversity. Ecology Letters, 7, 584-600. https://doi. org/10.1111/j.1461-0248.2004.00606.x

Morales-Reyes, M., Martín-López, B., Moleón, M., Mateo-Tomás, P., Botella, F., Margalida, A., ... Sánchez-Zapata, J. A. (2018). Farmer perceptions of the ecosystem services provided by scavengers: What who and to whom. Conservation Letters, 11, e12392. https://doi. org/10.1111/conl.12392

Morales-Reyes, Z., Sánchez-Zapata, J. A., Sebastián-González, E., Botella, F., Carrete, M., \& Moleón, M. (2017). Scavenging efficiency and red fox abundance in Mediterranean mountains with and without vultures. Acta Oecologica, 79, 81-88. https://doi.org/10.1016/j. actao.2016.12.012

Nogués-Bravo, D., Araújo, M. B., Romdal, T., \& Rahbek, C. (2008). Scale effects and human impact on the elevational species richness gradients. Nature, 453, 216-220. https://doi.org/10.1038/nature06812 
O'Bryan, C. J., Braczkowski, A. R., Beyer, H. L., Carter, N. H., Watson, J. E. M., \& McDonald- Madden, E. (2018). The contribution of predators and scavengers to human well-being. Nature Ecology and Evolution, 2, 229-236. https://doi.org/10.1002/fee.1776

Ogada, D. L., Torchin, M. E., Kinnaird, M. F., \& Ezenwa, V. O. (2012). Effects of vulture declines on facultative scavengers and potential implications for mammalian disease transmission. Conservation Biology, 26, 453-460. https://doi.org/10.1111/j.1523-1739.2012.01827.x

Oksanen, J., Blanchet, F. G., Friendly, M., Kindt, R., Legendre, P., McGlinn, D., \& Wagner, H. (2017). vegan: Community ecology package. R package version 2.4-3. Retrieved from https://CRAN.R-project.org/ package $=$ vegan

Oro, D., Genovart, M., Tavecchia, G., Fowler, M. S., \& Martínez-Abraín, A. (2013). Ecological and evolutionary implications of food subsidies from humans. Ecology Letters, 16, 1501-1514. https://doi. org/10.1111/ele.12187

Pardo-Barquín, E., Mateo-Tomás, P., \& Olea, P. P. (2019). Habitat characteristics from local to landscape scales combine to shape vertebrate scavenging communities. Basic and Applied Ecology, 34, 126-139. https://doi.org/10.1016/j.baae.2018.08.005

Pereira, L. M., Owen-Smith, N., \& Moleón, M. (2014). Facultative predation and scavenging by mammalian carnivores: Seasonal, regional and intra-guild comparisons. Mammal Review, 44(1), 44-55. https:// doi.org/10.1111/mam.12005

Pianka, E. R. (1966). Latitudinal gradients in species diversity: A review of concepts. American Naturalist, 100, 33-46. https://doi. org/10.1086/282398

R Development Core Team. (2017). R: A language and environment for statistical computing. Vienna, Austria: R Foundation for Statistical Computing.

Ray, R.-R., Seibold, H., \& Heurich, M. (2014). Invertebrates outcompete vertebrate facultative scavengers in simulated lynx kills in the Bavarian Forest National Park, Germany. Animal Biodiversity and Conservation, 37(1), 77-88. https://doi.org/10.5167/uzh-130585

Read, J. L., Parkhurst, B., \& Delean, S. (2015). Can Australian bush birds be used as canaries? Detection of pervasive environmental impacts at an arid Australian mine site. EMU, 115, 117-125. https://doi. org/10.1071/MU14069

Read, J. L., \& Wilson, D. (2004). Scavengers and detritivores of kangaroo harvest offcuts in arid Australia. Wildlife Research, 31, 51-56. https:// doi.org/10.1071/WR02051

Rodell, M., Houser, P. R., Jambor, U., Gottschalck, J., Mitchell, K., Meng, C.-J., ... Toll, D. (2004). The global land data assimilation system. Bulletin of the American Meteorological Society, 85(3), 381-394. https ://doi.org/10.1175/BAMS-85-3-381

Schluter, D. (2016). Speciation, ecological opportunity, and latitude. American Naturalist, 187, 1-18. https://doi.org/10.1086/684193

Sebastián-González, E., Dalsgaard, B., Sandel, B., \& Guimarães, P. R. (2015). Macroecological trends in nestedness and modularity in seed-dispersal networks: Human impact matters. Global Ecology and Biogeography, 24, 293-303. https://doi.org/10.1111/ geb.12270

Sebastián-González, E., Moleón, M., Gibert, J. P., Botella, F., MateoTomás, P., Olea, P. P., ... Sánchez-Zapata, J. A. (2016). Nested species-rich networks of scavenging vertebrates support high levels of interspecific competition. Ecology, 97, 95-105. https://doi. org/10.1890/15-0212.1

Selva, N., \& Fortuna, M. A. (2007). The nested structure of a scavenger community. Proceedings of the Royal Society of London, Series B, 274, 1101-1108. https://doi.org/10.1098/rspb.2006.0232

Tucker, M. A., Böhning-Gaese, K., Fagan, W. F., Fryxell, J. M., Van Moorter, B., Alberts, S. C., ... Mueller, T. (2018). Moving in the Anthropocene: Global reductions in terrestrial mammalian movements. Science, 359, 466-469. https://doi.org/10.1126/scien ce.aam9712

Turner, K. L., Abernethy, E. F., Conner, L. M., Rhodes, O. E. Jr, \& Beasley, J. C. (2017). Abiotic and biotic factors modulate carrion fate and scavenging community dynamics. Ecology, 98(9), 2413-2424. https://doi. org/10.1002/ecy.1930

Venter, O., Sanderson, E. W., Magrach, A., Allan, J. R., Beher, J., Jones, K. R., ... Watson, J. E. M. (2016). Sixteen years of change in the global terrestrial human footprint and implications for biodiversity conservation. Nature Communications, 7, 12558. https://doi.org/10.1038/ ncomms12558

Weiss, D. J., Atkinson, P. M., Bhatt, S., Mappin, B., Hay, S. I., \& Gething, P. W. (2014). An effective approach for gap-filling continental scale remotely sensed time-series. ISPRS Journal of Photogrammetry and Remote Sensing, 98, 106-118. https://doi.org/10.1016/j.isprs jprs.2014.10.001

Willig, M. R., Kaufman, D. M., \& Stevens, R. D. (2003). Latitudinal gradients of biodiversity: Pattern, process, scale and synthesis. Annual Reviews in Ecology, Evolution and Systematics, 34, 273-309. https:// doi.org/10.1146/annurev.ecolsys.34.012103.144032

Wilson, D., \& Read, J. L. (2003). Kangaroo harvesters: Fertilizing the rangelands. Rangeland Journal, 25, 47-55. https://doi.org/10.1071/ RJ03007

Wilson, E. E., \& Wolkovich, E. M. (2011). Scavenging: How carnivores and carrion structure communities. Trends in Ecology \& Evolution, 26, 129-135. https://doi.org/10.1016/j.tree.2010.12.011

Wright, D. H. (1983). Species-energy theory: An extension of speciesarea theory. Oikos, 41, 496-506. https://doi.org/10.2307/3544109

Zuur, A. F., leno, E. N., \& Elphick, C. S. (2010). A protocol for data exploration to avoid common statistical problems. Methods in Ecology and Evolution, 1, 3-14. https://doi.org/10.1111/j.2041-210X.2009.00001.x

\section{SUPPORTING INFORMATION}

Additional supporting information may be found online in the Supporting Information section at the end of the article.

How to cite this article: Sebastián-González E, Barbosa JM, Pérez-García JM, et al. Scavenging in the Anthropocene: Human impact drives vertebrate scavenger species richness at a global scale. Glob Change Biol. 2019;25:3005-3017. https:// doi.org/10.1111/gcb.14708 